\title{
The Comparison of Bone Mineral Density Between Male Smokers and Non-Smokers
}

\author{
(1) Rahime Merve Uçar, ${ }^{1}$ (1) Kamile Marakoğlu, ${ }^{1}$ (1) Gonca Kara Gedik, ${ }^{2}$ \\ (D) Muhammet Kızmaz, ${ }^{1}$ (D) Funda Levendoğlư ${ }^{3}$ \\ 'Department of Family Medicine, Selçuk University Faculty of Medicine, Konya, Turkey \\ 2Department of Nuclear Medicine, Selçuk University Faculty of Medicine, Konya, Turkey \\ ${ }^{3}$ Department of Physical Medicine and Rehabilitation, Selçuk University Faculty of Medicine, Konya, Turkey
}

\section{ABSTRACT}

Objectives: Osteoporosis is one of the health issues caused by smoking. Osteoporosis is the most commonly seen bone disease and becoming a major public health issue due to extension of lifetime. Studies on detection of smoking related osteoporosis in males are limited in our country. Therefore we intended to assess the effects of smoking on bone mineral density in middle aged male patients alongside of related factors.

Methods: Our study is a case control type analytical research. We included 144 male smoker patients, aged between 30-60 years-old, and 100 male volunteers, never smoked. Bone mineral density (BMD) of the patients' lumbar spine (L1-3 and L2-4) and proximal femur (femur total, femur trochanter and wards triangle) regions of the individuals were measured anteroposteriorly by using dual energy $\mathrm{x}$-ray absorptiometer (DXA) method. Serum Ca, P, ALP, PTH and total vitamin D levels of the samples were studied.

Results: The means of L1-L4 lumbar spine bone mineral density, femoral neck bone mineral density, femoral trochanter bone mineral density and total femoral bone mineral density were significantly lower in the case group than the control group, according to DXA measurements $(p=0.017, p=0.047, p=0.005$ and $p=0.009$; respectively). There was a slightly strong correlation and a negative statistically significant difference between femoral trochanter BMD and both cigarette consumption (per-day) and packets-year $(r=-0.153, p=0.017$ and $r=-0.142, p=0.027$; respectively). The mean levels of serum calcium were significantly higher in the case group than the control group $(p=0.018)$.

Please cite this article as: Uçar RM, Marakoğlu K, Kara Gedik G, Kızmaz M, Levendoğlu F. The Comparison of Bone Mineral Density Between Male Smokers and Non-Smokers. Anatol J

Family Med 2019;2(1):19-26.

Address for correspondence: Dr. Kamile Marakoğlu. Selçuk Üniversitesi Tıp Fakültesi, Aile Hekimliği Anabilim Dalı, Konya, Turkey

Phone: +90 33224150 00-44 36

E-mail: kmarakoglu@yahoo.com

Received Date: 17.11.2018

Accepted Date: 12.12.2018

Published online: 30.04 .2019

OCopyright 2019 by Turkish Foundation of Family Medicine - Available online at www.anatoljfm.org

Conclusion: We can conclude that smoking has decreasing effects on bone mineral density.

Keywords: Bone mineral density; osteoporosis, smoker

\section{INTRODUCTION}

Osteoporosis (OP) is a systemic skeletal disease characterized by decreasing in bone density and increasing in bone fragility due to deterioration of bone micro structure. ${ }^{[1]} \mathrm{OP}$ is the most seen bone disease and becoming a major public health issue. OP is seen less often among males than females due to bone and muscle mass of males being higher, compared to females, absence of menopause and shorter life expectancy of males. ${ }^{[2]}$ In addition, mortality and morbidity rates of osteoporosis are higher among males than females, which increase the attention of researchers on subjects such as protective measures and treatment of male osteoporosis. The etiology for approximately $40 \%$ of the male osteoporosis cases is unknown and these cases are diagnosed as idiopathic male osteoporosis. ${ }^{[2]}$ While OP prevalence in developed countries is $13-19 \%$ in males over 50 years-old, this rate increases up to $70 \%$ in pa- 
tients over 80 years old. ${ }^{[3,4]}$ OP prevalence in Turkey is $7.5 \%$ in male and $12.9 \%$ in female patients over 50 years old..$^{[5]}$

Osteoporosis is one of the health issues caused by smoking. ${ }^{[6]}$ Smoking as a risk factor for both bone mass loss and fractures had been recognized about 30 years ago.

Premenopausal and postmenopausal females had been resulted revealing the relations between smoking and low bone mineral density (BMD) and osteoporosis related fractures. ${ }^{[6]}$ The effect of smoking on BMD had been attempted to be explained by various mechanisms. Smokers, when compared to non-smokers, had been observed skinnier and having a lower body fat index. ${ }^{[7]}$ Moreover, besides the adult body mass index, birth weight had been reported as effecting the smoking related osteoporosis development and smoking of lower birth weighted male babies had been shown to increase the osteoporosis development. ${ }^{[8]}$ Smoking is also thought to have direct toxic effects on males. Animal studies had shown the nicotine disturbing new bone development. ${ }^{[9]}$ Smoking had been detected as decreasing calcium absorption. ${ }^{[10]}$ Furthermore, unhealthy behaviors such as increased alcohol usage, less physical activity, less sun light exposure and less calcium intake are observed more often in smokers. ${ }^{[11]}$

At the present time, smoking is stated to reach an important magnitude worldwide. Smoking rates are $47 \%$ for males and $12 \%$ for females, according to World Health Organization. It has been predicted that $20 \%$ of females will be smokers in developing countries by the year 2025. ${ }^{[12]}$ Global Adult Tobacco Research conducted by Turkish Statistical Institute in 2012 had reported the smoking rate as $41.4 \%$ in males and 13.1 in females and $27 \%$ in general. ${ }^{[13]}$

Smoking is a major public health problem in our country alongside many countries worldwide and this condition is triggering other smoking related diseases and discomforts. Studies on detection of smoking related osteoporosis in males are limited in our country. Therefore, we intended to assess the effects of smoking on osteoporosis.

\section{METHOD}

\section{Subjects and Study Design}

Our study is a case control type analytical research. We included 144 smoker male patients aged between 30-60 years-old, applied to Selcuk University Smoking Cessation Polyclinic between September $15^{\text {th }}, 2012$ and April $15^{\text {th }}, 2013$ to case group. One hundred never-smoked male patients between 30-60 years of age, who applied to Periodical Examination Polyclinic, were also included in the study. Patients with lesser rate of 10 packs per year and patients who smoke less than 10 cigarettes per day were not included to the case group. All individuals in the study were tried to be grouped in similarly by age, body mass index (BMI), and socioeconomic status. Heights and weights of the patients who were included to the study were measured with standard platform scale and height scale, after they removed their shoes, jackets and other excess clothes and BMI was calculated using weight/height ${ }^{2}\left(\mathrm{~m}^{2}\right)$ formula. Our study had been approved by Selcuk University Medical Faculty ethics committee on January $19^{\text {th }}, 2012$ with the decision numbered 2012/1.

\section{Risk Factors}

Data involving demographic features, osteoporosis risk factors, daily physical activities, sports involvement, dietary habits and smoking levels of the participants was obtained using a questionnaire involving 37 questions and the forms were filled with the patients by face to face. Patients with a family history of osteoporotic fracture history, or with a history of any of these situations as fracture after minor trauma, use of glucocorticosteroid for more than 3 months, hyperthyroidism, excessive alcohol usage, secondary osteoporosis risk factors (Type 1 diabetes mellitus, osteogenesis imperfecta, hyperthyroidism, hypogonadism, chronic malnutrition, malabsorption syndromes such as celiac disease, ulcerative colitis, chronic liver disease and patients with the history of chemotherapy); patients with low body weight $(<57 \mathrm{~kg})$, patients who lost more than $10 \%$ of their weights around the age of 25 , patients receiving chronic heparin treatment or anticonvulsants and patients with rheumatoid arthritis were considered as having clinical risk factors regarding to osteoporosis and they all are excluded from the study.

\section{Bone Mass Density Measurements}

BMD measurements of the patients' lumbar vertebrae (L13 and L2-4) and proximal femur (femur total, femur trochanter and wards triangle) regions were done anteroposteriorly by using dual energy $\mathrm{x}$-ray absorptiometer (DXA) method. Measurements were conducted anteroposteriorly on the vertebrae (L1-4 AP spine vertebrae) and left femur upper end.

\section{Biochemical Measurements}

Blood samples of the individuals were collected to jelly bottles from the antecubital region after cleaning the skin with $70 \%$ alcohol. Samples were centrifuged at $4000 \mathrm{rpm}$ for 10 minutes. Calcium $(\mathrm{Ca})$, phosphorus $(\mathrm{P})$, alkaline phosphatase (ALP), parathyroid hormone (PTH), and total vitamin D levels of the samples were studied in the Selcuk University Medical Faculty Biochemistry Laboratory. 


\section{Statistical Analysis}

All data was assessed using SPSS 16.0 statistical program package. Data assessment was done using numbers, percentages, mean values and standard deviation. Chi-square test was used to assess frequency distribution for categorical data. To assess the measurements of 2 different groups according to one variable, Student-t test was used. Pearson correlation analysis was used to identify the relations between numerical variables. Correlation coefficient $(r)$ was considered weak between 0.000-0.249, intermediate when between 0.250-0.499, strong when between 0.500-0.749 and very strong when between 0.750-1.000. A $p$ value $<0.05$ was considered to have statistical significance. Covariance analysis was used. To compare more than two mean values; ANOVA analysis of variance was used.

\section{RESULTS}

Our study group was divided into two subgroups as cases $(n=144)$ and controls $(n=100)$. Mean age of the case group was $43.88 \pm 7.86$ and of the control group was $41.78 \pm 8.42$ and there was no statistical significance between the groups according to age $(p=0.054)$. Mean BMI of the case group was $26.45 \pm 3.30 \mathrm{~kg} / \mathrm{m}^{2}$ and of the control group was $27.06 \pm 2.77 \mathrm{~kg} / \mathrm{m}^{2}$ and there was no statistical significance between two groups according to weight $(p=0.132)$. Smoking habit features of the smokers are in Table 1.

\section{Table 1. Smoking habit features of the smokers}

\section{Smoking habit features $(n=144)$}

\begin{tabular}{|c|c|c|c|c|}
\hline & Mean \pm SD & Med. & Min. & Max. \\
\hline First smoking age (years) & $16.72 \pm 4.33$ & 16 & 10 & 48 \\
\hline $\begin{array}{l}\text { Daily cigarette } \\
\text { consumption (per-day) }\end{array}$ & $27.18 \pm 8.23$ & 25 & 20 & 50 \\
\hline Smoking duration (years) & $26.00 \pm 8.37$ & 26 & 12 & 47 \\
\hline Packets (years) & $35.85 \pm 14.74$ & 33 & 15 & 92 \\
\hline Fagerström dependence values & $6.20 \pm 2.09$ & 6 & 1 & 10 \\
\hline
\end{tabular}

SD: Standard deviation; Med.: Median; Min.: Minimum; Max.: Maximum.
According to DXA measurements, the means of L1-L4 lumbar spine bone mineral density, femoral neck bone mineral density, femoral trochanter bone mineral density and total femoral bone mineral density were significantly lower in the case group than the control group $(p=0.017, p=0.047$, $p=0.005$ and $p=0.009$, respectively) (Table 2). Covariance analysis was used to eliminate the effects of other variables that can affect BMD (calcium intake, coffee e.g.). No other factor has been found to be effective.

There was a slightly strong correlation and a negative, statistically significant difference between femoral trochanter BMD and both cigarette consumption (per-day) and packets-years ( $r=-0.153, p=0.017 ; r=-0.142, p=0.027$, respectively). There was a slightly strong correlation and a negative, statistically significant difference between Fagerström DP and L1-L4 BMD, F. trochanter BMD, Femur total BMD $(r=-0.130, p=0.042 ; r=-0.175, p=0.006 ; r=-0.158, p=0.013$, respectively). L1-L4 BMD, femoral neck BMD, femoral trochanter BMD and femoral total BMD were correlated with Smoking Duration. Correlation was slightly strong and negative, statistically significant difference $(r=-0.139, p=0.030$; $r=-0.161, p=0.012 ; r=-0.174, p=0.007 ; r=-0.184, p=0.004$, respectively) (Table 3).

When the participants were categorized into three groups as non-smokers, smokers with fewer than thirty packetsyears (15-29 Packets-years) and smokers with more than thirty packets-years; F. trochanter BMD mean and Femur total BMD mean were significantly lower in smokers with more than thirty packets-years than non-smokers $(p=0.021$, $\mathrm{p}=0.020$ ) (Table 4).

Mean serum calcium levels were significantly higher in the case group than the control group $(p=0.018)$. There was no statistically significant difference between the case group and the control group for serum phosphorus, PTH, ALP and vitamin $D(p>0.050)$ (Table 5).

L1-L4 BMD measurements of the case group were normal in $77(53.47 \%)$ of the patients according to $T$ and $Z$ scores and $67(46.53 \%)$ of the patients were osteopenic and osteporotic. L1-L4 BMD measurements of the control group

Table 2. Bone mineral density comparison of the smokers and non-Smokers

\begin{tabular}{|c|c|c|c|c|}
\hline BMD measurements $\left(\mathrm{g} / \mathrm{cm}^{2}\right)$ & $\begin{array}{c}\text { Smokers }(n=144) \\
(\text { Mean } \pm S D)\end{array}$ & $\begin{array}{c}\text { Non-smokers }(n=100) \\
(\text { Mean } \pm \text { SD) }\end{array}$ & $\mathbf{t}$ & $\mathbf{p}$ \\
\hline L1-L4 & $1.146 \pm 0.142$ & $1.192 \pm 0.156$ & 2.411 & 0.017 \\
\hline Femur trochanter & $0.869 \pm 0.106$ & $0.910 \pm 0.121$ & 2.826 & 0.005 \\
\hline Femur total & $1.051 \pm 0.119$ & $1.095 \pm 0.137$ & 2.628 & 0.009 \\
\hline
\end{tabular}

SD: Standard deviation; t: Student t test level. 
Table 3. Daily cigarette consumption, packs year, fagerstörm point and BMD measurement correlation

\begin{tabular}{|c|c|c|c|c|c|c|c|c|}
\hline & \multicolumn{2}{|c|}{$\begin{array}{r}\text { L1-L4 } \\
\text { BMD }\end{array}$} & \multicolumn{2}{|c|}{$\begin{array}{c}\text { Femur neck } \\
\text { BMD }\end{array}$} & \multicolumn{2}{|c|}{$\begin{array}{c}\text { F. trochanter } \\
\text { BMD }\end{array}$} & \multicolumn{2}{|c|}{$\begin{array}{c}\text { Femur total } \\
\text { BMD }\end{array}$} \\
\hline & $\mathbf{r}$ & $\mathbf{p}$ & $\mathbf{r}$ & $\mathbf{p}$ & $\mathbf{r}$ & $\mathbf{p}$ & $\mathbf{r}$ & $\mathbf{p}$ \\
\hline Cigarette consumption (per-day) & -0.117 & 0.068 & -0.082 & 0.199 & $-0.153^{*}$ & 0.017 & -0.125 & 0.052 \\
\hline Packets years & -0.106 & 0.100 & -0.101 & 0.114 & $-0.142^{*}$ & 0.027 & $-0.133^{*}$ & 0.037 \\
\hline Fagerström DP & $-0.130^{*}$ & 0.042 & -0.108 & 0.091 & $-0.175^{* *}$ & 0.006 & $-0.158^{*}$ & 0.013 \\
\hline
\end{tabular}

Table 4. BMD measurement comparison between smokers and non-smokers according to grouped packets years amount

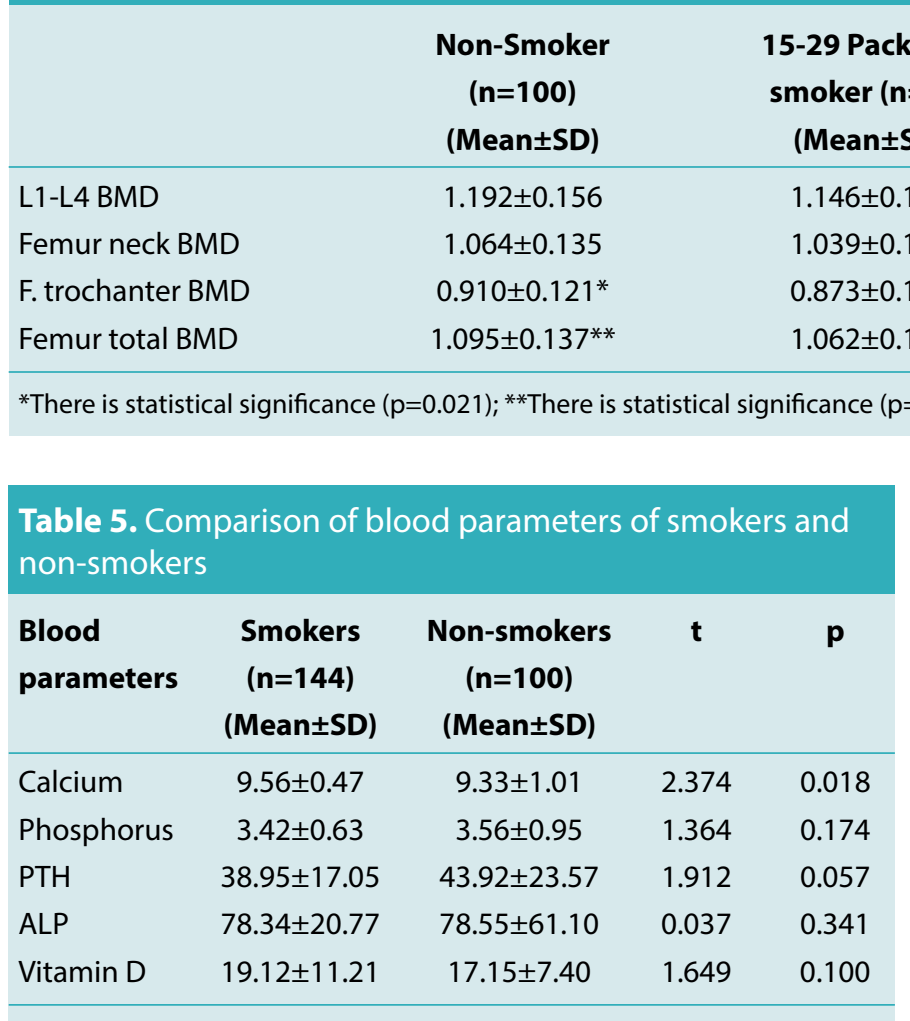

SD: Standard deviation; PTH: Parathyroid hormone; ALP: Alkaline phosphatase; t: Student t test level.

were normal in 67 (67.00\%) of the patients and 33 (33.00\%) was osteopenic and osteoporotic according to $\mathrm{T}$ and $\mathrm{Z}$ scores. There was a statistically significant difference between the groups $(p=0.035)$. Femur neck BMD measurements were normal in $112(77.78 \%)$ of the case group and $32(22.22 \%)$ was osteopenic according to T and Z scores. Femur neck BMD measurements were normal in $82(82.00 \%)$ of the control group and $18(18.00 \%)$ was osteopenic and osteoporotic according to $T$ and $Z$ scores and no statistical significance was detected between two groups $(p=0.422)$.

Femur trochanter BMD measurement results were normal in 97 (67.53\%) of the patients in the case group according to $T$ and $Z$ scores and 48 (32.47\%) was osteopenic and osteoporotic and in the control group, 75 (75.00\%) was normal and 25 (25.00\%) was osteopenic. No statistically significant difference was detected between groups $(p=0.198)$. Femur total BMD measurements were normal in 113 (78.47\%) of the case group patients and 31 (21.53\%) was osteopenic and osteoporotic according to $T$ and $Z$ scores and in the control group, these rates were $86(86.00 \%)$ and $14(14.00 \%)$, respectively. No statistical significance was detected between the two group ( $p=0.136$ ) (Table 6).

No statistically significant differences were detected when the case and the control groups were compared regarding to dietary habits and physical exercise rates.

\section{DISCUSSION}

We have detected significantly lower BMD values among smoker males' L1-L4 vertebrae, femur neck and total femur parameters compared to non-smokers. Smoking was reported as a risk factor for osteoporosis in many studies and smokers having lower BMD values and higher pelvis fracture risk were also reported in many studies. ${ }^{[14]}$ Semenda et al. had detected that bone loss was higher as $44 \%$ in smokers compared to the on-smokers in their study conducted on 111 twin males by measuring radius shaft BMD 16 years apart and they found their data statistically significant. ${ }^{[15]}$ Law and Hackshaw had made the meta analysis of $29 \mathrm{sec}-$ 
Table 6. T and Z scores comparison of smokers and non-smokers

\begin{tabular}{|c|c|c|c|c|c|c|c|c|}
\hline & \multicolumn{2}{|c|}{$\begin{array}{l}\text { Smoker } \\
(n=144)\end{array}$} & \multicolumn{2}{|c|}{$\begin{array}{c}\text { Non-smoker } \\
(n=100)\end{array}$} & \multicolumn{2}{|c|}{ Total } & \multirow[t]{2}{*}{$x^{2}$} & \multirow[t]{2}{*}{$\mathbf{p}$} \\
\hline & $\mathbf{n}$ & $\%$ & $\mathbf{n}$ & $\%$ & $\mathbf{n}$ & $\%$ & & \\
\hline \multicolumn{9}{|l|}{ L1-L4 } \\
\hline Normal & 77 & 53.5 & 67 & 67.0 & 144 & 59.0 & 4.465 & 0.035 \\
\hline Osteopenic & 67 & 46.5 & 33 & 33.0 & 100 & 41.0 & & \\
\hline \multicolumn{9}{|l|}{ Femur neck } \\
\hline Normal & 112 & 77.8 & 82 & 82.0 & 194 & 79.5 & 0.646 & 0.422 \\
\hline Osteopenic & 32 & 22.2 & 18 & 18.0 & 50 & 20.5 & & \\
\hline \multicolumn{9}{|l|}{ Osteoporotic } \\
\hline \multicolumn{9}{|l|}{ Osteoporotic } \\
\hline \multicolumn{9}{|l|}{ Femur total } \\
\hline Normal & 113 & 78.5 & 86 & 86.0 & 199 & 81.6 & 2.223 & 0.136 \\
\hline Osteopenic & 31 & 21.5 & 14 & 14.0 & 45 & 18.4 & & \\
\hline \multicolumn{9}{|l|}{ Osteoporotic } \\
\hline Total & 144 & 100.0 & 100 & 100.0 & 244 & 100 & & \\
\hline
\end{tabular}

*Males over 50 years of age were assessed with T score and under 50 years of age were assessed with Z score.

tional studies and found no differences between smoker and non-smoker individuals around 50 years-old. ${ }^{[16]}$ They had observed a difference increasing with age. As an example, they had detected that smokers around 70 years-old had $41 \%$ more pelvic fractures compared to non-smokers. Statistically significant increased fracture risk had been detected for any kind of fracture in smokers. And this risk had been detected to be higher in males compared to females, significantly. In this study, we had detected that smoking is a significant risk factor for future fractures and the highest risk is for pelvic fractures. Many studies suggest that bone loss related to smoking is mostly in old aged males. ${ }^{[15]}$ In addition to this, Valimaki et al. had shown in one of their study that there is a relation between smoking and males in adolescent period and early adulthood. ${ }^{[17]}$ Also, OrtegoContono et al. had detected lower BMD values in heavy smokers ( $>20$ cigarette/day) compared to non-smokers in their study conducted on 20-45 aged healthy males. ${ }^{[18]}$ In a study based on 3 population- based studies conducted in 2000 had reported that $19 \%$ of all pelvic fractures can be attributed to smoking. Pelvic fracture rates had been reported as increasing alongside the tobacco exposure rates in both genders. ${ }^{[14]}$ Ward and Klesges had reported in their meta-analysis that smokers have lower BMD values in totalbody (pelvis, forearm, calcaneus but especially pelvis) measurements. ${ }^{[19]}$ They had observed these effects espe- cially among over 60 years-old individuals. They had not detected any significant effect on individuals younger than 40 years old. In the Minos study, ex-smokers had been detected to have lower BMD values compared to non-smokers. Ex-smokers were observed to have similar BMD values compared to continuous smokers. ${ }^{[7]}$ Kanis et al. had reported after their comparison of 10 prospective cohort studies, 59232 individual and 5 content that present smokers had $25 \%$ increase for fracture risk compared to individuals that had never smoked and they had detected the highest risk for pelvic fractures. ${ }^{[20]}$ Also, the risk for all osteoporotic fractures except the pelvic fractures had been reported to have lower relative risk values in males compared to females. Supervia et al. had detected lower BMD values in lumbar vertebrae of smoker males compared to non-smoker males. ${ }^{[21]}$

Lorenton et al. had observed lower BMD values in lumbar vertebrae, femur neck and femur trochanter of smokers compared to non-smokers in their study conducted with 1068 male individuals of $18-80$ years-old. ${ }^{[22]}$ They also found tibia cortical thickness lesser in smokers compared to nonsmokers. Tamaki et al. had reported lower BMD rates on lumbar vertebrae in smokers compared to non-smokers and ex-smokers. ${ }^{[23]}$ When ex-smokers combined with continuous smokers, they had observed lower BMD values of lumbar vertebrae compared to non-smokers. Eleftheriou 
et al. had studied on 723 males between 16-28 years-old in their study and found that pelvis and femur neck BMD values were lower in ex-smokers and continuous smokers compared to non-smokers. ${ }^{[24]}$

In our study, we found a significant negative relationship between daily smoking rate and femur trochanter BMD values. As daily cigarette consumption increases, femur trochanter value were observed to be decreasing. We also found a significant negative relation between the packyear parameter and femur trochanter BMD and femur total $B M D$ values. There were significant negative correlations between smoking duration and L1-L4 BMD and femur neck, femur trochanter BMD, femur total BMD. In our study, we also observed that femur trochanter and femur total BMD values were statistically significantly decreasing in patients smoked over 30 packs/year compared to non-smokers.

There are many studies in the literature that show the effects of smoking on bone tissue and especially in regards to smoking duration, total smoking amount and Pack-year parameters. ${ }^{[18,23,25,26]}$ When individuals using 20 or more cigarettes per day were compared to non-smokers, they had been observed to have significantly lower BMD values. ${ }^{[18]}$ Vogel et al. had compared $<1$ pack of cigarette and $\geq 1$ pack of cigarette users with non-smokers, and they had observed significantly smaller BMD values on calcaneus bone. ${ }^{[25]}$ They had detected significant relation with bone mass density decrease on calcaneus bone with smoking amount and almost significant relationship between radius bone and smoking amount. When the relation between BMD and smoking amount had been assessed, they had observed the BMD value decreasing on calcaneus and distal radius bones as the smoking duration increases and they also reported the smoking duration as effective as smoking amount, regarding to bone loss. When individuals who had never smoked were compared to the individuals who quit smoking, they had observed BMD values progressively increasing as the time after cessation of the smoking increases. Also, calcaneus BMD measurements of ex-smokers were observed between the values of smokers and non-smokers. When over 20 packs/year smokers were compared to non-smokers, distal radius and calcaneus BMD values were observed significantly decreased. But when over 20 packs/ year smokers had been divided into subgroups, a progressive decrease had not been observed.

Ward and Klesges had assessed 86 independent studies on their metaanalysis. ${ }^{[19]}$ They had found a negative correlation between smoking dosage (packs/year, daily smoking amount, smoking duration as years) and bone measurements. The toxic effect of smoking in young adults had been observed in heavy smokers (>1 pack/day). ${ }^{[17,18]}$ Slemenda et al. had found a negative correlation between daily smoking amount and proximal radius BMD values in their study conducted on 111 twin males with 2 different measurements on radius shaft, in 16 years apart. Individuals smoking over 2 packs per day had been detected to lose $58 \%$ of their BMD in 16 years. ${ }^{[15]}$ Tamaki et al. had found a significant negative relationship between lumbar vertebrae and total pelvis BMD measurement values and daily smoking amount and Pack/year parameters. ${ }^{[23]}$ Especially in individuals smoking $\geq 22$ cigarettes per day, lumbar vertebrae BMD values were detected significantly lower when compared to non-smokers. In a study based on 3 population based studies, published in year 2000; smokers had been divided into subgroups as 1-14 packs/year, 15-29 packs/year and over 30 packs/year. After the confounding variables (age, BMI, alcohol usage, physical activity rate, etc.) were adjusted, a weak relation between Pack/year and pelvis fracture, but the linear gradient was observed to stay significant in both genders. Males who quit smoking were observed to have a lower risk for pelvis fracture compared to continuous smokers and this risk was observed to be decreasing over time. Individuals who had quit smoking over 5 years, had been observed to have pelvis fracture risk close to the individuals who had never smoked. ${ }^{[14]}$ In contrast to this, Meyer et al. had found no risk decrease in males after 5 years of smoking cessation in the Norwegian cohort study. ${ }^{[27]}$ Alongside this data, they had found significantly higher fracture risk in heavy smokers ( $\geq 15$ per day). Some studies had found higher risk for pelvic fractures for males and females who quit smoking and they had a value between smokers and nonsmokers. ${ }^{[28]}$ These findings suggest positive effects of smoking cessation on pelvic fracture risk, but some of the effects of smoking on bone tissue are irreversible. Insignificant results had usually come from small studies (total 222 males) or with individuals smoking lower amounts per day (12 or less per day). ${ }^{[26,29]}$ We found a statistically significant relation between smoking duration and the BMD values of all region measurements in our study. This data suggests that there is more bone loss in individuals smoking for longer periods and is compatible with literature data.

In our study we found no statistically significant difference between the serum vitamin D levels of smokers and non- smokers. Also, the parameters of PTH, ALP and P were also statistically insignificant. But interestingly, in our study serum calcium levels of smokers were found significantly higher compared to non-smokers'. Padmavathi et al. had detected serum calcium, phosphate and ALP levels higher in smokers compared to non-smokers in their study conducted on males aged between 27-35 years. ${ }^{[30]}$ They also found a negative correlation between serum calcium levels and HDL levels and attributed the higher calcium levels to 
lower HDL levels in smokers. They had suggested the HDL as a calcium channel modulator. This shows that, serum calcium levels as an indicator of bone resorption, can be increased in smokers. Bone resorption parameters have been found higher in smokers than non-smokers in recent studies. ${ }^{[30-34]}$ This explanation supports our findings of increased calcium levels. But this finding is also in contrast with other data in the literature. There is a need for new studies with larger subject sample sizes. As mentioned before; the high calcium levels were attributed to low HDL levels in the study of Padmavathi et al. We did not measured HDL levels in our study. In many studies; lower vitamin D levels were shown in smokers and also there are studies reporting no statistically significant differences. ${ }^{[7,31]}$ Data regarding to effects of smoking on PTH concentrations is limited and inconsistent. There are studies reporting PTH levels as lower, similar and higher in smokers compared to non-smokers. ${ }^{[7]}$ The mechanisms under these differences are not fully studied. Alongside these factors such as weight, alcohol consumption, sun exposure, physical activity, low calcium and vitamin $D$ intake can be hold responsible for inconsistent PTH levels. ${ }^{[7]}$ Lange et al. had measured vitamin D levels of 626 males in their study between 1984-2003 and they had applied detailed physical examination and questionnaires in every 3-5 years regularly. They had found no statistical significant relation between smoking and vitamin $D$ levels. ${ }^{[32]}$ Supervia et al. had compared the serum calcium phosphor, 1.25 hydroxyvitamin D levels between smokers and non-smokers and found no significant difference. ${ }^{[21]}$ They found significantly higher PTH levels in smokers compared to non-smokers. Lorentzon et al. had found lower vitamin $D$ levels in smokers. ${ }^{[22]}$ They had not found a statistical difference for PTH levels. Grimnes et al. had found serum 25 $(\mathrm{OH}) \mathrm{D}$ levels higher in smokers compared to non-smokers and they had attributed the finding to the measurement method. ${ }^{[33]}$ They had found no statistically significant difference regarding to serum calcium levels. Cutillas-Marco et al. had detected vitamin D deficiency risk in smokers in their study and found smoking correlated with low PTH levels. ${ }^{[34]}$ They also found no statistical difference regarding to serum calcium levels. No significant correlation between daily smoking amount and $25(\mathrm{OH}) \mathrm{D}$ and PTH levels were found. In two sectional cohort studies, lower 25-hydroxyvitamin and 1.25-OH2-D levels were observed in smokers compared to non-smokers. ${ }^{[7,22]}$ Various effects of smoking on serum calcium levels were shown. ${ }^{[7]}$ There are evidences regarding the smoking alters the calciotropic hormone metabolism by changing the gastrointestinal calcium intake. ${ }^{[7]}$ Also, the reason for us to find no statistically significant difference between smokers and non-smokers could be our small case sample size. Alongside this, vitamin D levels were low in both groups. Included individuals mostly working in closed environments and not having healthy dietary habits could be the reason. Our findings support the literature data regarding to bone mineral density decreasing effects of smoking.

\section{Disclosures}

Ethics Committee Approval: Our study had been approved by Selcuk University Medical Faculty ethics committee on January $19^{\text {th }}, 2012$ with the decision numbered 2012/1.

Peer-review: Externally peer-reviewed.

Conflict of Interest: The authors report no conflict of interest.

Finance disclosure: This study was supported by Selcuk University Scientific Research and Projects Committee (Project Number: 12102010).

Authorship Contributions: Concept - R.M.U., K.M.; Design R.M.U., K.M., G.K.G., F.L.; Supervision - K.M.; Materials - R.M.U., K.M., G.K.G., F.L.; Data collection \&/or processing - R.M.U.; Analysis and/ or interpretation - R.M.U., K.M.; Literature search - R.M.U., K.M., M.K.; Writing - R.M.U., K.M., M.K.; Critical review - R.M.U., K.M., M.K.

\section{REFERENCES}

1. Eastell R, Boyle IT, Compston J, Cooper C, Fogelman I, Francis $\mathrm{RM}$, et al. Management of male osteoporosis: report of the UK Consensus Group. QJM 1998;91(2):71-92. [CrossRef]

2. Gilbert SM, McKiernan JM. Epidemiology of male osteoporosis and prostate cancer. Curr Opin Urol 2005;15:23-7. [CrossRef]

3. Cheng N, Green ME. Osteoporosis screening for men. Can Fam Physician 2008;54:1140-1.

4. Randell A, Sambrook PN, Nguyen TV, Lapsley H, Jones G, Kelly PJ, et al. Direct clinical and welfare costs of osteoporotic fractures in elderly men and women. Osteoporosis Int 1995;5:427-32.

5. Tuzun S, Eskiyurt N, Akarirmak U, Saridogan M, Johansson H, McCloskey E, et al. Turkish Osteoporosis Society. The impact of a FRAX-based intervention threshold in Turkey: the FRAXTURK study. Arch Osteoporos 2012;7:229-35. [CrossRef]

6. Jenkins MR, Denison AV. Smoking status as a predictor of hip fracture risk in postmenopausal women of northwest Texas. Prev Chronic Dis 2008;5(1):A09.

7. Szulc P, Garnero P, Claustrat B, Marchand F, Duboeuf F, Delmas PD. Increased bone resorption in moderate smokers with low body weight: The Minos Study. J Clin Endocrinol Metab 2002;87:666-74. [CrossRef]

8. Moinuddin MM, Jameson KA, Syddall HE, Sayer AA, Martin HJ, Robinson $S$, et al. Cigarette smoking, birthweight and osteoporosis in adulthood: results from the Hertfordshire cohort study. Open Rheumatol J 2008;2:33-37. [CrossRef]

9. Riebel GD, Boden SD, Whitesides TE, Hutton WC. The effect of nicotine on incorporation of cancellous bone graft in an animal model. Spine 1995;20(20):2198-202. [CrossRef] 
10. Krall EA, DawsonHughes B. Smoking and bone loss among postmenopausal women. J Bone Miner Res 1991;6:331-8.

11. Halperin AC, Smith SS, Heiligenstein E, Brown D, Fleming MF. Cigarette smoking and associated health risks among students at five universities. Nicotine Tob Res 2010;12:96-104.

12. Seltzer V. Smoking and women's health. Int J Gynaecol Obstet 2000;70:159-63. [CrossRef]

13. Turkish Statistical Institute (2012). Available from http://www. tuik.gov.tr/PreHaberBultenleri.do?id=1314 2. (Access date:23 Nov 2018)

14. Hoidrup S, Prescott E, Sorensen TI, Gottchau A, Lauritzen JB, SchrollM Grønbaek M. Tobacco smoking and risk of hip fracture in men and women. Int J Epidemiol 2000;29:253-9.

15. Slemenda CW, Christian JC, Reed T, Reister TK, Williams CJ, Johnston CC Jr. Long-term bone loss in men: Effects of genetic and environmental factors. Ann Intern Med 1992;117:286-91.

16. Law MR, Hackshaw AK. A meta-analysis of cigarette smoking, bone mineral density and risk of hip fracture: recognition of a major effect. BMJ 1997;315:841-6. [CrossRef]

17. Valimaki MJ, Karkkainen M, Lamberg-Allardt C, Laitinen $K$, Alhava E, Heikkinen J, et al. Exercise, smoking, and calcium intake during adolescence and early adulthood as determinants of peak bone mass: Cardiovascular Risk in Young Finns Study Group. Br Med J 1994;309:230-5. [CrossRef]

18. Ortego-Centeno N, Munoz-Torres M, Jodar E, HernandezQuero J, Jurado-Duce A, de la Higuera Torres-Puchol J. Effect of tobacco consumption on bone mineral den- sity in healthy young males. Calcif Tissue Int 1997;60:496-500. [CrossRef]

19. Ward KD, Klesges RC. A meta-analysis of the effects of cigarette smoking on bone mineral density. Calcif Tissue Int 2001;68:259-70. [CrossRef]

20. Kanis JA, Jhonell O, Oden A, Jhonsson H, De Laet C, Eisman JA, et al. Smoking and fracture risk: a meta-analysis. Osteoporos Int 2005;16:155-62. [CrossRef]

21. Supervía A, Nogués X, Enjuanes A, Vila J, Mellibovsky L, Serrano, $S$ Aubía J, et al. Effect of smoking and smoking cessation on bone mass, bone remodelling, vitamin D, PTH and sex hormones. J Musculoskelet Neuronal Interact 2006;6:234-41.

22. Lorentzon M, Mellström D, Haug E, Ohlsson C. Smoking is associated with lower bone mineral density and reduced cortical thickness in young men. J Clin Endocrinol Metab 2007;92(2):497-503. [CrossRef]

23. Tamaki J, Iki M, Fujita Y, Kouda K, Yura A, Kadowaki E, et al. Im- pact of smoking on bone mineral density and bone metabolism in elderly men: the Fujiwara-kyo osteoporosis risk in men (FORMEN) study. Osteoporos Int 2011;22:133-41. [CrossRef]

24. Eleftheriou KI, Rawal JS, James LE, Payne JR, Loosemore M, Pennell DJ, et al. Bone structure and geometry in young men: The influence of smoking, alcohol intake and physical activity. Bone 2013;52:17-26. [CrossRef]

25. Vogel JM, Davis JW, Nomura A, Wasnich RD, Ross PD. The effects of smoking on bone mass and the rates of bone loss among elderly Japanese-American men. J Bone Miner Res 1997;12:1495-501. [CrossRef]

26. Sneve M, Emaus N, Joakimsen RM, Jorde R. The association between serum parathyroid hormone and bone mineral density and the impact of smoking: the Tromso Study. Eur J Endocrinol 2008;158:401-9. [CrossRef]

27. Meyer HE, Tverdal A, Falch JA. Risk factors for hip fracture in middle-aged Norwegian women and men. Am J Epidemiol 1993;137:1203-11. [CrossRef]

28. Paganini-Hill A, Chao A, Ross RK, Henderson BE. Exercise and other factors in the prevention of hip fracture: The Leisure World Study. Epidemiology 1991;2:16-25. [CrossRef]

29. Kroger H, Laitinen K. Bone mineral density measured by dualenergy X-ray absorptiometry in normal men.Eur J Clin Invest 1992;22:454-60. [CrossRef]

30. Padmavathi P, Reddy VD, Varadacharyulu N. Influence of chronic cigarette smoking on serum biochemical profile in male human volunteers. J Health ScI 2009;55:265-70. [CrossRef]

31. Snijder MB, Lips P, Seidell JC, Visser M, Deeg DJ, Dekker JM, et al. Vitamin $D$ status and parathyroid hormone levels in relation to blood pressure: a population-based study in older men and women. Journal of Internal Medicine 2007;261:558-65.

32. Lange EN, Sparrow D, Vokonas V, Litonjua AA. Vitamin D deficiency, smoking, and lung function in the normative aging study. Am J Respir Crit Care Med 2012;186:616-21. [CrossRef]

33. Grimnes G, Almaas B, Eggen AE, Emaus N, Figenschau $Y$, Hopstock LA. Effect of smoking on the serum levels of 25-hydroxyvitamin $D$ depends on the assay employed. Eur J Endocrinol 2010;163(2):339-48. [CrossRef]

34. Cutillas-Marco E, Fuertes-Prosper A, Grant BW, MoralesSuárez-Varela M. Vitamin D deficiency in South Europe: effect of smoking and aging. Photodermatol Photoimmunol Photomed 2012;28(3):159-61. [CrossRef] 